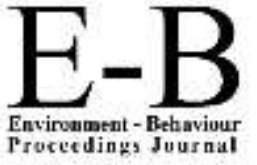
Proceeding, Juurnal

5th ABRA International Conference on Quality of Life
Holiday Villa Langkawi, Langkawi Island, Malaysia, 15-16 Dec 2021

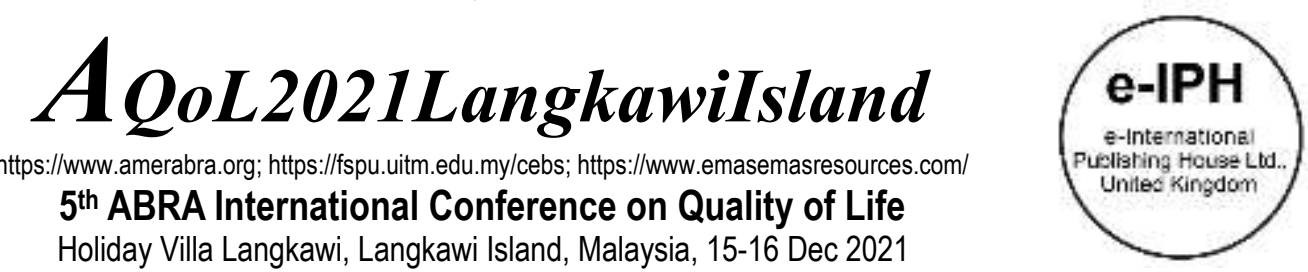

AoL2021LangkawiIsland
https://www.amerabra.org; https://fspu.uitm.edu.my/cebs; https://www.emasemasresources.com/
56RA ABRA International Conference on Quality of Life
Holiday Villa Langkawi, Langkawi Island, Malaysia, 15-16 Dec 2021

\title{
Motivation and Hygiene Factors of Work Satisfaction among Intensive Care Nurses in Selangor
}

\author{
Wan Marina Wan Ismail 1, 2, Norhaini Majid ${ }^{1}$, Suryanto Suryanto ${ }^{3}$ \\ ${ }^{1}$ Centre for Nursing Studies, Faculty of Health Sciences, Universiti Teknologi MARA, Malaysia, ${ }^{2}$ Serdang Hospital, Selangor, Malaysia, \\ ${ }^{3}$ School of Nursing, Faculty of Medicine, Universitas Brawijaya, Indonesia \\ wanmarina13@gmail.com, majidnorhaini@gmail.com, suryanto.s@ub.ac.id \\ Tel: +60193991110
}

\begin{abstract}
The work satisfaction among nurses is essential in a healthcare system. Nurse satisfaction may refer to the motivation to stay in the nursing profession and the organization in which they are satisfied with. The study aims to determine the level of work satisfaction among Intensive Care nurses and examined the relationship between Herzberg's motivation and hygiene factors. The study used a quantitative design with a theoretical framework based on Herzberg's theory. A total of 218 nurses from the Intensive Care Unit were selected. The results showed that overall, of the nurses had a moderate level of work satisfaction.
\end{abstract}

Keywords: Work satisfaction, motivation, hygiene, nurses

eISSN: 2398-42870 2021. The Authors. Published for AMER ABRA cE-Bs by e-International Publishing House, Ltd., UK. This is an open access article under the CC BYNCND license (http://creativecommons. org/licenses/by-nc-nd/4.0/). Peer-review under responsibility of AMER (Association of Malaysian Environment-Behaviour Researchers), ABRA (Association of Behavioural Researchers on Asians/Africans/Arabians) and cE-Bs (Centre for Environment-Behaviour Studies), Faculty of Architecture, Planning \& Surveying, Universiti Teknologi MARA, Malaysia.

DOI: https://doi.org/10.21834/ebpj.v6i18.3090

\subsection{Introduction}

The work satisfaction concept among nurses is essential, especially during critical situations in handling patients. According to Jiang et al. (2017), nurse satisfaction may refer to the motivation to stay in the nursing profession and the organisation they are satisfied with. Jones et al. stated that nursing staff retention is vital to the health care industry (2015). The shortage of nurses in most countries is well documented, and sometimes it has reached such an extent that some hospitals are offering bonuses to nurses to lure them from other employers. In their study, Jiang et al. (2017) revealed that emergency department nurses in Shanghai have a high level of burnout, related to an intention to leave their professions. The frustration due to work burden needs to be taken most seriously, as insufficient RN-patient ratios also increase the risk of poor patient outcomes and deaths in hospital wards (Ball et al., 2018; Griffits et al., 2016; Jones et al., 2015). Nurses often work in unsatisfactory conditions with inadequate staffing and a shortage of basic supplies. Nurses working in government sectors will be paid according to the specific area with basic post allowances. Most of the nurses in Malaysia working in the critical area treating patients worked more than the set essential ratio of care (by Malaysia Nursing Board, 2012) of 1:1 versus the current incidents of 1:2. A thorough understanding of nurses' work satisfaction is therefore critical to nursing administration. Suppose nurse leaders comprehend what makes nurses tick, motivated and satisfied. In that case, they can adapt and make appropriate changes to facilitate nurse satisfaction and indirectly improve patient satisfaction, which will also improve employee retention rate.

In these situations, nurse administrators should apply the classic work satisfaction research of the past, such as Fredrick Herzberg's Motivation Versus Hygiene Theory (Herzberg, 1959). Plus, they should use that information as a foundation upon which to build current

eISSN: 2398-4287@ 2021. The Authors. Published for AMER ABRA cE-Bs by e-International Publishing House, Ltd., UK. This is an open access article under the CC BYNCND license (http://creativecommons.org/licenses/by-nc-nd/4.0/). Peer-review under responsibility of AMER (Association of Malaysian Environment-Behaviour Researchers), ABRA (Association of Behavioural Researchers on Asians/Africans/Arabians) and cE-Bs (Centre for Environment-Behaviour Studies), Faculty of Architecture, Planning \& Surveying, Universiti Teknologi MARA, Malaysia.

DOI: https://doi.org/10.21834/ebpj.v6i18.3090 
knowledge. Therefore, the purpose of this study is to determine factors that influence critical care nurses in non-Specialist and with Specialist Hospital the level of work satisfaction through an examination of the relationship between Herzberg's motivation and hygiene factors and the nurses' overall work satisfaction.

\subsection{Literature Review}

According to Suliman, and Aljezawi (2018), work satisfaction among healthcare workers who work with disabled patients revealed low levels of work satisfaction among healthcare workers. For example, the nurses had the lowest work satisfaction while doctors were most satisfied with their jobs. Other studies suggest a strong association between low levels of work satisfaction and organisational factors (Geleto et al., 2015). Further studies conducted among healthcare workers also show the importance of interpersonal relationships in work satisfaction (Hotchkiss et al., 2015). On another note, some studies have concluded that teamwork leads to higher job satisfaction, increased patient safety, improved patient care, and increased patient satisfaction. For example, a survey by Tasneem et al. (2018) tested an intervention to promote teamwork and engagement among nursing staff in a medical unit of an acute care hospital.

Al-Hamdan et al. (2016) on the correlation of work satisfaction among healthcare professionals in Jordan revealed a significant relationship between educational level and work satisfaction. Respondents with a diploma holder reported the highest level of job satisfaction. Employees with more extended experience were also more satisfied than those with limited experience.

Buchan et al. (2018) in the United States explored how satisfied mental health professionals were with different aspects of their jobs. Participants in this study appeared to be happy with aspects of their employment that involved patient care, e.g., providing psychological services, but surprisingly, they were less satisfied with administrative tasks. Suliman, and Aljezawi (2018), in their study on nurses' work satisfaction, found that nurses' satisfaction from the job was strongly correlated with their intent to stay.

Hertzberg's theory has identified the two factors as a motivation factor and hygiene factor. The motivation factor is the high-level needs that will enable the motivation drive in all employees to attain the highest performance and quality of work. Therefore, it was a high-level intrinsic factor that is directly associated with work.

Therefore, this study will investigate the relationship between the nurses' work satisfaction and the motivation and hygiene factors among the critical care nurses in a public hospital in Malaysia.

\subsection{Methodology}

The study is a descriptive cross-sectional survey designed to collect information regarding motivation and hygiene factors of work satisfaction among nurses in the intensive care unit at Selangor State.

\subsection{Research Setting}

A sample size of 228 based on the population of 298 has been selected to participate in the research, based on the population of staff working in critical care unit in 2 tertiary and 2 secondary hospitals at Selangor state at the time of this study.

\subsection{Sample}

A sample size of 228 based on the population of 298 has been selected to participate in the research, based on the number of staff working in critical care units in two tertiary and two secondary hospitals at Selangor state at the time of this study. Total 218 questionnaires were returned out of 228 questionnaires to the researcher. Ten questionnaires were found incomplete. Hence, the usable questionnaires for this research were 218.

\subsection{Research Instrument}

Two instruments will use to gather data for this study. The first instrument was a demographic questionnaire designed by the researcher. The questionnaire collected information about the characteristics of the participants, including age, gender, education, and experience in nursing. The demographic questionnaire also included two narrative questions. The first question inquired about the subject's work satisfaction and why they are or are not satisfied. The second question asks what aspects of their job most lead to their satisfaction or dissatisfaction with their job and why.

\subsection{Sample Criteria}

Nurses who were not directly involved in inpatient care, the nurse manager and those who work per diem were excluded from the study. Inclusion Criteria included all registered nurses who work in ICU > 6/12, registered nurses with various backgrounds and levels of experience eligible to participate in this study. Exclusion Criteria for this study are nurses who were not directly involved in patient care, the nurse managers and those who work per diem were excluded from this study, staff nurses who refused to participate, a staff nurse who does not rely on duty during the study period. 


\subsection{Procedure of Data Analysis}

The data collected from the surveys were coded and entered the Statistical Package for the Social Sciences (SPSS), version 11.0 for analysis. The questionnaire was coded and analysed using descriptive correlation (Pearson's $r$ Correlation Co-efficient), ANOVA and TTest statistics.

\subsection{Findings}

Demographic data for the entire sample $(n=218)$ respondent. The characteristic included age, gender, ethnicity, marital status, level of education, years of work experience, distance from hospital and intention to leave.

The sample consisted of more than $89 \%(n=19)$ females than males $11 \%(n=24)$. Majority $86.7 \%(n=189)$ were Malay, followed by $6.9 \%(n=15)$ Chinese and $6.4 \%(n=14)$ Indian. Also found that $69.3 \%(n=151)$ nurses were married, $29.4 \%(n=64)$ are still single while $10.1 \%(n=3)$ are being divorced. The ages of the participant varied from the $20-30$ years old category $67.8 \%(n=148), 31-40$ years $(30.7 \%)$ and 41 and above $1.4 \%$. Component of level of education, it is found that mostly $88.5 \%(n=193)$ of nurses had a Diploma in Nursing, $10.1 \%(n=22)$ had a bachelor's degree and $1.4 \%(n=3)$ had a certificate in nursing.

Their years of experience in nursing were quite varied. Years of experienced ranged from 110 respondents $50.5 \%$ falling into the five years or less category, respondents $47.7 \%$ ( $n=104)$ falling in $6-15$ years, $1.4 \%(n=3)$ within $16-25$ years and only one nurse had more than 26 years of experiences. In the demographic questionnaire, there was one question asked about the nurse's intention to leave their nursing unit, facility, or field of nursing and no intention to leave the profession. Nearly half of the nurses, $47.2 \%$ ( $n=103$ ), wanted to leave their nursing unit, $15.6 \%$ in their current facility and $29.8 \%$ not leaving, but $7.3 \%(n=16)$ will intend to leave the field of nursing. Majority of the respondents $61.9 \%(n=135)$ working distance are less than $16 \mathrm{~km}, 33.5 \%(n=73)$ within $17-48 \mathrm{~km}$ and only $4.6 \%(n=10)$ working distances more than 49 kilometres.

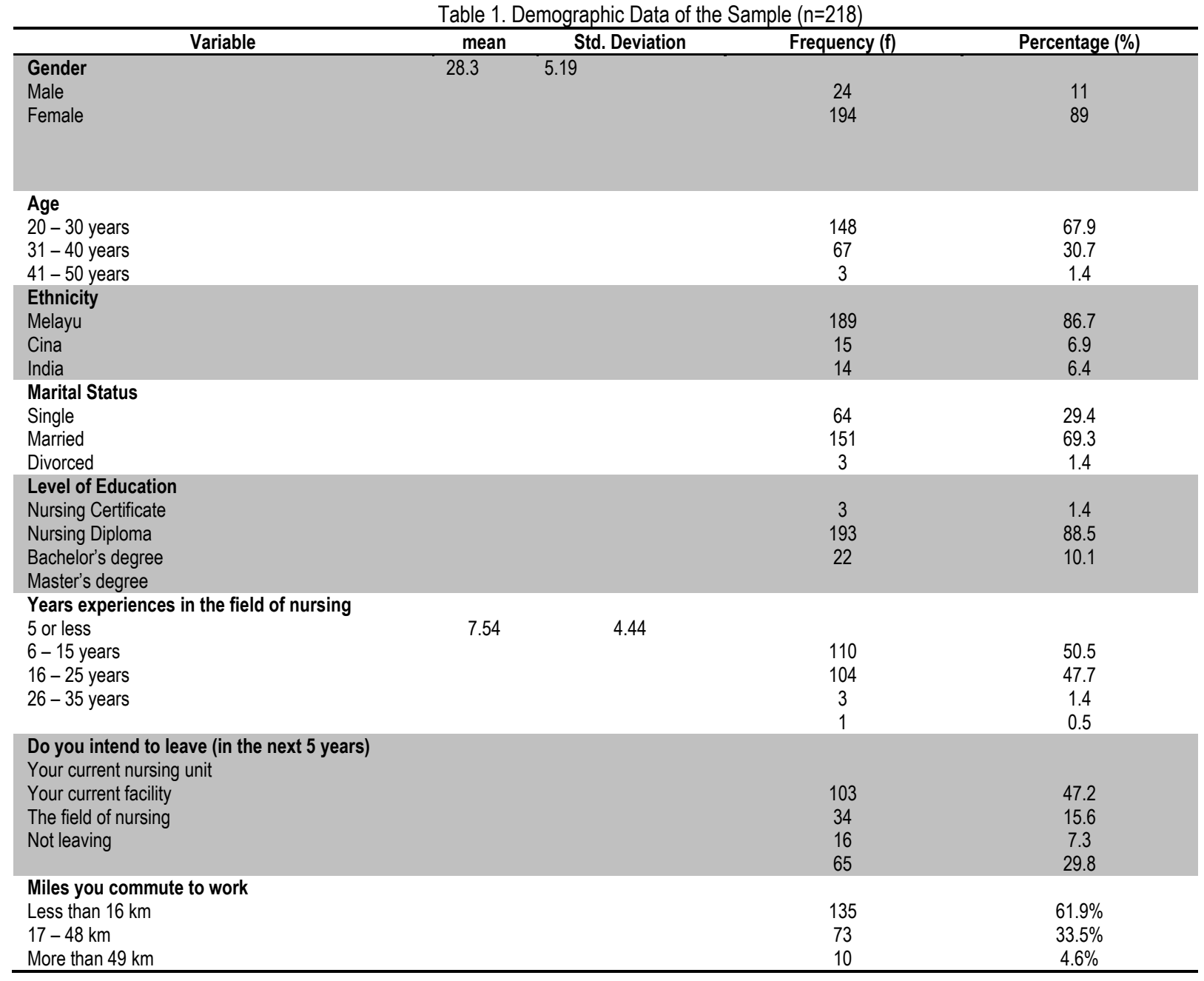

\subsection{To determine the level of work satisfaction among nurses.}

Overall, the mean score for work satisfaction is 4.03 with a standard deviation of $0.82(\mathrm{Cl} 3.915,4.13)$. The study results show the respondents were satisfied just above the mid-point of the scale, defined as 3.5. This finding is similar to other studies that have found that nurses typically had reasonable job satisfaction. In identifying the overall level of job satisfaction among nurses both in tertiary and 
secondary hospitals, the study found that the mean score for overall work satisfaction is higher in the secondary hospitals, 4.18 , with a standard deviation of 0.69 . In contrast, for tertiary hospitals, the mean score is 3.93 , with a standard deviation of 0.88 . This study suggested that nurses' overall work satisfaction in secondary hospitals is higher than that of tertiary hospitals.

4.2 To determine the relationships between motivation and hygiene factors.

Table: 2 Correlation between Motivation and Hygiene Factors

$\begin{array}{cc}r & p \text { value } \\ 0.798 & P<0.001\end{array}$

The output of Pearson correlation showed a significant positive linear relationship between Motivation and Hygiene factors. This result showed that an increasing level of motivation factors will increase the hygiene factors.

4.3 To determine whether there is any relationships between demographic characteristics and nurses work satisfaction.

Table: 3 Relationships between demographic characteristic and nurses work satisfaction between Motivation and Hygiene Factors

\begin{tabular}{|c|c|c|c|}
\hline Variables & $X \pm S D$ & $f$ & $p$ value \\
\hline $\begin{array}{c}\text { Age } \\
20-30 \\
31-40 \\
41-50\end{array}$ & $\begin{array}{l}3.82 \pm 0.78 \\
4.48 \pm 0.72 \\
4.29 \pm 1.07\end{array}$ & 17.214 & $P<0.001$ \\
\hline $\begin{array}{l}\text { Experiences } \\
<5 \text { years } \\
6-10 \text { years } \\
11>\text { years }\end{array}$ & $\begin{array}{l}3.71 \pm 0.73 \\
4.09 \pm 0.87 \\
4.56 \pm 0.66\end{array}$ & 24.70 & $P<0.001$ \\
\hline $\begin{array}{c}\text { Distance to work } \\
\quad<16 \mathrm{~km} \\
17-48 \mathrm{~km} \\
49-85 \mathrm{~km}\end{array}$ & $\begin{array}{l}4.14 \pm 0.83 \\
3.84 \pm 0.80 \\
3.83 \pm 0.71\end{array}$ & 3.349 & $P<0.037$ \\
\hline $\begin{array}{l}\text { Ethnicity } \\
\text { Melayu } \\
\text { Cina } \\
\text { India }\end{array}$ & $\begin{array}{l}4.03 \pm 0.85 \\
3.77 \pm 0.53 \\
4.11 \pm 0.79\end{array}$ & 0.840 & 0.433 \\
\hline $\begin{array}{l}\text { Marital Status } \\
\text { Single } \\
\text { Married } \\
\text { Divorced }\end{array}$ & $\begin{array}{l}4.10 \pm 0.79 \\
4.00 \pm 0.84 \\
3.51 \pm 0.26\end{array}$ & 0.890 & 0.409 \\
\hline $\begin{array}{l}\text { Level of Education } \\
\text { Certificate } \\
\text { Diploma } \\
\text { Bachelor Degree }\end{array}$ & $\begin{array}{l}4.23 \pm 0.70 \\
3.98 \pm 0.84 \\
4.37 \pm 0.61\end{array}$ & 2.260 & 0.107 \\
\hline $\begin{array}{l}\text { Intention to Leave } \\
\text { Current nursing unit } \\
\text { Current facility } \\
\text { Field of Nursing } \\
\text { Not Intend to leave }\end{array}$ & $\begin{array}{l}3.67 \pm 0.66 \\
3.77 \pm 0.80 \\
3.52 \pm 0.46 \\
4.84 \pm 0.51\end{array}$ & 53.05 & $P<0.001$ \\
\hline
\end{tabular}

Post Hoc analysis (Bonferroni) shows that nurses aged between 20 - 30 years old had significantly lower overall work satisfaction than those aged between $31-40$ years. $p$-value $<0.001$. Nurses who had experience in nursing less than five years had a significantly lower overall work satisfaction than those who had experience working as a nurse between $6-10$ years.

$p$-value $<0.001$. The finding also showed that nurses who had less than 6 kilometres of distance to work had significantly higher overall work satisfaction than those who had a long distance to work between $17-48$ kilometres. $p$-value $<0.037$ shows that nurses who do not intend to leave have a higher score of work satisfaction than those who intend to leave the current nursing unit, current facility, or field of nursing. p-value $<0.001$

\subsection{Discussion}


This study aimed to determine the relationship between motivation and hygiene factors and identify the relationship between work satisfaction and demographic characteristics among nurses. In addition, this study provided information about the samples' level of job satisfaction and the relationships between Herzberg's Theory.

\subsection{Level of the Nurses overall work Satisfaction}

In this first objective, the study also revealed a statistically significant finding between mean motivation factors between tertiary and secondary hospitals. However, there is no significant difference in hygiene factors between both category hospitals. The study shows that motivation factors do influence work satisfaction among nurses in critical care units in both categories of hospitals. In Herzberg's Theory, work satisfaction covers both Motivation and Hygiene factors.

Thus, with the results of this study, there is an ardent need for related nursing organisations, hospitals, nursing division and Ministry of Health to embark on a positive transformation to increase the level of motivation factors such as achievement, recognition, responsibility work itself and advancement, supervision, employment benefits among nurses. Neglecting the welfare of the nurses will have a direct negative impact on the nursing profession, particularly to over 90,000 nurses in public hospitals. According to K. Doig, S. Beck. (2019) , he stated that job dissatisfaction has both and long term effects on the image of nursing professions.

\subsection{Relationships between Motivation and Hygiene Factors}

This result showed that an increasing level of motivation factors will increase the hygiene factors. According to Geleto et al. (2015), motivation to improve performance is linked to a feeling of self-fulfilment, achievement and recognition. These feelings can be influenced through effective management performance via evaluation of a manager in ensuring their staffs are competent and then to continue providing motivation to the workers (Hotchkiss, et al. (2015). Herzberg's theory also mentions that to improve motivation and increase staff performance, attention should be given to motivating factors, for example, by increasing the individual's sense of achievement and to demonstrate recognition of that achievement. In general, few studies surveyed it was revealed that although they were conducted using different sample sizes and under various working conditions, the frequency of intrinsic factors mentioned as related to job satisfaction was considerably higher than that of extrinsic factors.

\subsection{Relationships between Demographic Data and Total work satisfaction.}

The outcome of this study proved that nurses who are older are more satisfied with their work compared to the younger nurses. This study results also showed similarity with earlier studies done that revealed that older employees are generally satisfied with their job, although this may change as their chances of advancement get diminished and they face the reality of retirement. Previous research also states that job satisfaction increases with increasing age (Halcomb E, et al, 2018). Studies also demonstrated that age has a bearing on job satisfaction, with younger nurses being less satisfied than older nurses. This was because as the individual matures, the goals and expectations become more realistic and therefore resulting in higher level of work satisfaction.

The experience in the field of nursing less than 5 years had a significantly lower total overall work satisfaction compared to those nurses who had experience working as a nurse between $6-10$ years. People are an organisation's greatest resource. Attracting and retaining the right people is critical to the success of an organisation, particularly service-oriented organisation Lu et al. (2016). The human environment focuses on human aspects that influence and employees' performance and job satisfaction.

The result discovered that the respondents who do not intend to leave have a higher score of work satisfaction compared to those who have intention to leave the current nursing unit, current facility, or nursing field. Previous studies from Lu et.al. (2016) concluded that patients, who stayed onwards where nursing staff felt more exhausted or more frequently and expressed their intention to quit, were less satisfied with their medical care. This study confirmed the importance of understanding nurses' job satisfaction and intention to quit as both concepts, which would contribute to patient outcomes. Several recent studies further confirmed that nurses job satisfaction contributed to the perceptual levels of patient satisfaction with nursing care, which is one of the most important clinical outcome indicators (Suliman, M., \& Aljezawi, M, 2018).

Findings showed that nurses travelling a long distance to work would have lower work satisfaction when compared with nurses who are living nearer to the workplace. Nurses who stay further from work may be experiencing possible stress while making their journey to work due to work traffic, an earlier start of the journey and the need to settle their house shores much quicker. If they are late to work, other issues and problems shall arise. In the study done by Tasneem et al. (2018), they found that commuting studies often indirectly approach job satisfaction by emphasising stress as the main factor.

\subsection{Conclusion and Recommendations}

In conclusion, the study identified that nurses in this study had moderate levels of work satisfaction. The results also found that there was a strong positive correlation between motivation and hygiene factors. Further, they also revealed there is a relationship between age, year of experience working as nurses, distances to working place and the nurses who had the intention to leave either unit, facilities, or the profession altogether. A qualitative study can be used in the future to know in depth on specific areas affecting work satisfaction which be studied are stress levels, quality of formal leadership, patient ratio and equity, scheduling, and benefits.

Therefore, with the study outcome, the nursing administration, nursing practice and nurse educators must have a high level of cooperation to handle these issues. They need to come up with a thorough guideline of working practices, more effective clinical systems, and more holistic learning culture, doing all within their power to meet these needs. The results can also help in developing policies and guidelines that could lead to an improvement in nurses work satisfaction and, therefore, better patient satisfaction in terms of nursing care. 
This done, naturally, it will lead to an elevated nursing career to professionalism and increase the quality of an organisation. Improving both motivation and hygiene factors will provides the context in line with the aspirations of healthcare professionals to increase work or job satisfaction and consequently have a positive effect on individual, organizational and quality of health care services.

\section{Acknowledgement}

We thank our colleagues from Universiti Teknologi MARA who provided insight and expertise that greatly assisted the research. Thank you to all participants for their support during data collection.

\section{Paper Contribution to Related Field of Study}

The result of this study perhaps could be used to develop a policy and guidelines on human resource management and career development for the nurses in the future.

\section{References}

Al-Hamdan, Z., Manojlovich, M., \& Tanima, B. (2016). Jordanian nursing work environments, intent to stay, and job satisfaction. Journal of Nursing Scholarship, 49(1), 103110. https://doi.org/10.1111/jnu. 12265

Ball, J. E., Bruyneel, L., Aiken, L. H., Sermeus, W., Sloane, D. M., Rafferty, A. M., Lindqvist, R., Tishelman, C., \& Griffiths, P. (2018). Post-operative mortality, missed care and nurse staffing in nine countries: A cross-sectional study. International Journal of Nursing Studies, 78, 10-15. https://doi.org/10.1016/j.jinurstu.2017.08.004

Bonenberger M, Aikins M, Akweongo P, Wyss K. The effects of health worker motivation and job satisfaction on turnover intention in Ghana: a cross-sectional study. Hum Resour Health. 2014;12:43.

Buchan J, Shaffer FA, Catton H. Policy Brief. Nurse Retention. 2018. International Center on Nurse Migration. https://www.icn.ch/sites/default/files/inlinefiles/2018_ICNM\%20Nurse\%20retention.pdf . Accessed 8 July 2018.

Cicolini G, Comparcini D, Simonetti V. Workplace empowerment and nurses' job satisfaction: a systematic literature review. J Nurs Manag. 2014 Oct;22(7):855-71.

Doig, K., \& Beck, S. (2019) Factors contributing to the retention of clinical laboratory personnel Clin. Lab. Sci., 18 (1)

Hotchkiss, D., Banteyerga, H., \& Tharaney, M., (2015). Job satisfaction and motivation among public sector health workers: evidence from Ethiopia. Hum. Resour. Health, 13 (1), pp. 83-94

Halcomb E, Smyth E, McInnes S. Job satisfaction and career intentions of registered nurses in primary health care: an integrative review. BMC Family Practice ( 2018$) 19: 136$.

Geleto, A., Baraki, N., Atomsa, G., \& Dessie, Y. (2015). Job satisfaction and associated factors among health care providers at public health institutions in Harari region, eastern Ethiopia: a cross-sectional study.BMC Res. Notes, 8 (1) (2015)

Griffiths, P., Ball, J., Drennan, J., Dall'Ora, C., Jones, J., Maruotti, A., Pope, C., Recio Saucedo, A., \& Simon, M. (2016). Nurse staffing and patient outcomes: Strengths and limitations of the evidence to inform policy and practice. A review and discussion paper based on evidence reviewed for the National Institute for Health and Care Excellence Safe Staffing Guideline Development. International Journal of Nursing Studies, 63, 213-225. https://doi.org/10.1016/j.jinurstu.2016.03.012

Jiang, H., Ma, L., Gao, C., Li, T., Huang, L., \& Huang, W. (2017). Satisfaction, Burnout and intention to stay of emergency nurses in Shanghai. Emergency Medicine Journal, 34(7), 448-453. https://doi.org/10.1136/emermed-2016-205886

Jones, T. L., Hamilton, P., \& Murry, N. (2015). Unfinished nursing care, missed care, and implicitly rationed care: State of the science review. International Journal of Nursing Studies, 52(6), 1121-1137. https://doi.org/10.1016/j.jpurstu.2015.02.012

Kosteas, Y. (2010). Job satisfaction and promotions.Ind. Relat.: J. Econ. Soc., 50 (1) , pp. 174-19

Lambrou P, Kontodimopoulos N, Niakas D. Motivation and job satisfaction among medical and nursing staff in a Cyprus public general hospital. Hum Resour Health. 2010;8:26.

Lu, Y., Hu, X., Huang, X., \& Zhuang, X., Guo, P., L. Feng, L., et al. (2016). Job satisfaction and associated factors among healthcare staff: a cross-sectional study in Guangdong Province, China BMJ Open, 6 (7), Article e011388

Lu H, While AE, Barribal KL. Job satisfaction among nurses: a literature review. Int J Nurs Stud. 2005;42:211-27

Lorber M, Skela SB. Job satisfaction of nurses and identifying factors of job satisfaction in Slovenian hospitals. Croat Med J. 2012;53(3):263-70.

Munyewende, P., Rispel, L., \& Chirwa, T. (2014), Positive practice environments influence job satisfaction of primary health care clinic nursing managers in two South African provinces. Hum. Resour. Health, 12 (1)

Suliman, M., \& Aljezawi, M. (2018). Nurses' work environment: Indicators of satisfaction. Journal of Nursing Management, 26(5), 525-530. https://doi.org/10.1111/jonm.12577

Tasneem, S., Cagatan, A., Avci, M., \& Basustaoglu, A. (2018).Job satisfaction of health service providers working in a public tertiary care hospital of Pakistan. Open 
Wan Ismail. W.M., et.al., AQoL2021, 5th ABRA International Conference on Quality of Life, Holiday Villa Langkawi, Malaysia, 15-16 Dec 2021, E-BPJ, 6(18), Dec 2021 (pp.133-139

Publ. Health J., 11 (1), pp. 17-27

Twigg D, McCullough K. Nurse retention: a review of strategies to create and enhance positive practice environments in clinical settings. Int J Nurs Stud. 2014;51:85-92. 